\title{
AC 2009-512: A COMPARISON OF THE ATTITUDES AND MOTIVATION OF STUDENTS IN AN INTRODUCTORY TECHNICAL GRAPHICS COURSE
}

\section{Jeremy Ernst, North Carolina State University}

Jeremy V. Ernst is an Assistant Professor in the Department of Mathematics, Science, and Technology Education at North Carolina State University. He currently teaches a variety of courses and supervises student teachers in the Technology Education Program. Jeremy specializes in research involving instruction, learning, and visualization for university students, students with disabilities and other at-risk populations in Career and Technical Education. He also has curriculum research and development experiences in technology, trade and industrial education. He can be reached by email at jeremy_ernst@ncsu.edu.

\section{Aaron Clark, North Carolina State University}

Aaron C. Clark is an Associate Professor of Technology Education and Graphic Communications at North Carolina State University in Raleigh, North Carolina. He received his B.S. and M.S. in Technology and Technology Education and earned his doctoral degree in Technology Education. His teaching specialties at both graduate and undergraduate levels are in areas related to visual theory, 3-D modeling, gaming education and technical animation. Research areas include curriculum development, graphics education and scientific/technical visualization. He presents and publishes in both technical/technology education and engineering education. He is currently a Co-PI on the new GRIDc grant that brings green research into the technology classroom and has recently completed three grants related to visualization and education and has started new research in areas related to STEM integration and gaming. His latest series of CDs are titled "VisTE: Visualization in Technology Education" that are designed to bring scientific visualization into math, science, and technology education classrooms.

\section{Alice Scales, North Carolina State University}

Alice Y. Scales is the Assistant Department Head of the Department of Mathematics, Science, and Technology Education and Coordinator of the Graphic Communications Program at North Carolina State University. She has taught at North Carolina State University since 1988. She has a B.S. in Science Education, a M.Ed. in Industrial Arts Education, and an Ed.D. in Occupational Education. At NC State University, she teaches introductory engineering graphics courses that include CAD, desktop publishing, and web site development. 


\title{
A Comparison of the Attitudes and Motivation of Students in an Introductory Technical Graphics Course: A Mix Methods Analysis
}

\begin{abstract}
In the Fall semester of 2007, students in introductory engineering graphics courses at North Carolina State University (NCSU) were given a survey as well as motivation test to examine their attitudes and motivation to learn material in an introductory technical graphics course. This survey provided the Graphic Communications Program at NCSU with a look at the ways in which their classes achieve and fail in their mission to teach graphic concepts, methodology, and an appreciation of the function of graphics in professional and personal day to-day experiences. The survey of 43 questions was based on the Colorado Learning Attitudes about Science Survey (CLASS) given by the Department of Physics at the University of Colorado. At the same time, an 81 question motivational survey was also given to the same students. Known as the Motivated Strategies for Learning Questionnaire (MSLQ), 31 questions related to motivation on this instrument focuses on six areas associated with student learning and motivation. Analyses of the data obtained from both of these surveys are examined and compared to determine how they relate to each other for individual students.
\end{abstract}

\section{Introduction}

Student attitudes and motivation are major topics of discussion and investigation in all educational disciplines. As part of this research several questions need to be answered. What can practitioners do to motivate students to learn? What role does attitude play in student interest and understanding? These questions, and others, contribute to the research query for this collective study that further investigates motivation and student attitudes toward courses in engineering graphics. Foundational to this line of investigation is a multi-disciplinary base of information associated with attitude and motivation, paired with specified process and methodology information in the study series.

\section{Motivation}

Many motivational processes are responsive to individual properties associated with tasks, the classroom, and the context of student engagement ${ }^{1}$. Literature on student motivation identifies many beliefs and constructs, but control, competence, and self-regulated strategic learning remain chief among them ${ }^{2}$. Both internal and external pressures assist in motivating adult learners ${ }^{3}$. As for the internal or intrinsic motivation, the attitude of self-determination is the nucleus of support for students ${ }^{4}$. This self-determined attitude is primarily a result of feeling competent. In adults, feelings of intellectual competence can be highly motivational when paired with internal pressures to serve as a driving force. Self-determination plays a major role in extrinsic motivation as well. This refers to "engaging in an activity to obtain an outcome 
separable from the activity itself", ${ }^{5}$ A recent study, conducted by Bye, Pushkar, \& Conway in $2007^{6}$, identifies intrinsic motivation as a predictor of a positive classroom effect, while selfimprovement and personal growth were found to be highly valued. In comparison with extrinsic goals from the same study, further differences were found between intrinsic and extrinsic motivation. Other studies have found that student motivation is directly linked to seeing value and meeting goals and beliefs about the importance of a given task or subject.

The value of motivation can be conceptualized through various approaches (e.g., learning vs. performance goals, intrinsic vs. extrinsic orientation, and interests); this motivational component effectively concerns students' motives for the completion of a task ${ }^{7}$. Self-efficacy has a major role in student motivation at both intrinsic and extrinsic levels. Students' perceived self-efficacy influences as the process by which he or she selects activities to participate in or complete. There are many circumstances where students assume and perform activities they deem themselves capable of completing and avoid those they believe to be beyond their ability ${ }^{8}$. Therefore, selfefficacy plays a major role in motivation in the classroom.

\section{Attitudes}

Students' attitudes about curricular and instructional practices in graphics education and other disciplines can be centered on their interests and beliefs associated with the content presented in a given course. Considering students' interests and beliefs can help create a logical form of instruction and can appeal to different student groups ${ }^{9}$. A large body of research in adult learning suggests that when instruction is provided in an appealing manner learning gains can be higher, especially related to student learning style ${ }^{10}$. When a faculty member engages student interests, their attitudes change and can become more motivated to learn the content presented ${ }^{11}$. Professional educators focus their attention on not only on increasing student understandings and knowledge, but also on helping to motivate students to appreciate what they are learning. If instruction motivates students, then they are likely to value their endeavors and alter their attitudes to seek future educational experiences similar to the ones they were motivated by ${ }^{12}$. Educational psychologists have conducted extensive research on student interests, attitudes, and motivation across a multitude of disciplines. Considering this, one primary objective for postsecondary education is to convey information and skills of practical value to students. It is relatively easy to assess the imparting of knowledge, but what students believe, appreciate, and value are just as important as identified course content ${ }^{13}$.

\section{The Study}

Considering the previously highlighted research, the investigators for this paper decided to examine existing standardized instrumentation used to assess student motivation and attitudinal variables. After conducting a review of literature, two instruments were identified considering appropriateness to the targeted study. The first instrument identified examines student attitudes about science classes, in particular physics and chemistry. The Colorado Learning Attitudes about Science Survey (CLASS) was developed to measure student beliefs and attitudes about science (i.e. physics). The original instrument was developed at the University of Colorado. The questions on the CLASS survey have undergone a rigorous validation and reliability process $^{14}$. The researchers adapted the instrument to specifically target engineering and technical graphics. Using the CLASS instrument as the template, the statement information was interchanged to produce an instrument for examining the attitudes of students toward engineering 
graphics and learning engineering graphics. The original survey was composed of 42 statements, which respondents rate on a five point Likert scale. The Likert scale utilized a range from one (1) "Strongly Agree" to five (5) "Strongly Disagree." The graphics version, known as the "North Carolina Learning Attitudes about Graphics Education Survey" (NCLAGES), consists of 43 statements as well as demographic questions. The simple word exchanges, from "science" to "graphics" and "graphics education," made the instrument appropriate for this investigation and was easily articulated over to the new content area for assessment.

The second instrument examined motivation. This instrument, known as the Motivated Strategies for Learning Questionnaire (MSLQ), was designed to evaluate college student's motivational orientation and use of varied learning strategies in college level courses ${ }^{15}$. The MSLQ is comprised of two sections, one for motivation and one for learning strategies. The motivation segment has 31 items that evaluate students' goals and value beliefs, students' beliefs about skills necessary to succeed, and test anxiety associated with a specific course ${ }^{16}$. Duncan \& McKeachie differentiate the learning strategy section as identifying students' use of different cognitive and metacognitive strategies as well as management of resources. The motivation section and the learning strategies section of the MSLQ include 81 items. Each item is rated using a 7-point Likert-type scale. The rating scale ranges from one (not at all true of me) to seven (very true of me).

The MSLQ was given to randomly selected introductory engineering graphics courses at NCSU during the fall of 2007. The NCLAGES, or hybrid of the CLASS instrument, was given to randomly selected introductory engineering graphics courses at NCSU during the spring semester of 2008. A summary of the research findings from these two studies is provided. The focus of study for this paper is the combining of data to perform a mixed methods analysis of data to identify relationships, if any, between student motivation and student attitudes about graphics related courses and content. The researchers worked within the constraints of a single introductory graphics course offering. Also, participates in the studies were selected from a targeted population that either required the course, or students who took the course for a general education credit. Although most analyses rely on the same instrument for different populations and or time structures, the researchers decided to use the same population and similar instruments that included both attitude and motivational areas. Both instruments were either designed for a broader population or were customized to fit the population in this study. With this type of research, population count plays a major role in the final outcomes. Considering this, the researchers could only use about two-thirds of the original data for this study. The first two studies were predicated on previous research (i.e. categorization, groupings), and this study is no exception. Below is an overall summation of the conclusions drawn from the first two research studies.

\section{MSLQ and NCLAGES Study Conclusions}

The population of the NCLAGES survey mainly consisted of sophomores majoring in engineering, with 91percent of the age range being between 18 and 21 . The majority of the participants considered themselves to be visual (58 percent) or multi-modal (36 percent) learners. Of the favorite hobbies listed by participants, the majority of were visual in nature consisting of two-dimensional (i.e. games) and three-dimensional (i.e. baseball, soccer) environments. Overall, 
most of the student participants indicated they felt the content covered in the course would be useful in their future job or career.

As indicated by the high Likert mean and mode for the real-world relations, students see how the content covered could be used beyond the course and appreciated the hands-on method of instruction associated with it. In terms of personal interest, the students felt the course's visual content and graphics could be used in everyday activities. The highest mode values for any grouping of statements in the study were found in the category of making sense of the information students learned in the course. Results of the study indicate that students view the information and processes taught in the course as a form of problem solving.

Many students see graphics education and visual skill development as a necessary basic in education, but difficult to learn. The researchers for this study concluded that students entering college understand that a difference exists between visual ability and visual skill and the need to increase their knowledge of visualization and communications. Students seemed comfortable using this knowledge to communicate technically and to visually problem-solve as well as understood the function of geometric constructions taught in the class. However, they also indicated they felt the need to have direct communication with the instructor and a need for high quality instruction. Overall, student's ratings in the category of attitudes, as indicated by the NCLAGES survey, concerning a fundamentals course in graphic communications was dominantly "strongly agree".

The results of the MSLQ survey found no significant differences between categories, but some interesting findings nevertheless. Item 13 ("If I can, I want to get better grades in this class than most of the other students") in the Extrinsic Goal Orientation subgroup, item 18 ("If I try hard enough, then I will understand the course materials") in the Control of Learning Beliefs subgroup, item 20 ('I'm confident I can do an excellent job on the assignments and test in the this course"), and item 21 ("I expect to do well in this class") of the Self-Efficacy Learning Performance subgroup were identified by the study as continuing motivational and learning factors for learning engineering graphics in the introductory engineering graphics course at NCSU. Considering that these statements "standout" among the others and that each in some way is associated with the level of understanding and the grade they wish to receive in class, grades are still a good motivation factor to consider with these participants. The ability to do well and see relevance in what is being taught is also paramount to a student's motivation in a course, like fundamentals of engineering graphics. From the data collected for this study, it can be observed that grades, relevance of content, and understanding subject matter are the main factors that affect students' motivation.

\section{Mix Methods Analysis Findings}

This study employs quantitative methods to integrate the results of two previous research studies: The Attitudes and Opinions of Students Toward Technical Graphics: Preliminary Survey Results $^{17}$ and Motivation and Strategies for Learning in a Fundamentals of Graphics Education Course $^{18}$. This analysis combines results from the NCLAGES and MSLQ instruments to assist in the identification of underlying processes of the samples. 
Summary statistics (Table 1) of the NCLAGES and MSLQ were calculated to provide a synopsis of the instrument results. The variance (0.28) and standard deviation (0.53) of the MSLQ results are minimal in comparison to the variance (1.10) and standard deviation (1.05) of the NCLAGES results indicating a smaller spread of participant ratings on the MSLQ. The standard error $(0.05)$ of the MSLQ results is smaller than the standard error (0.08) of the NCLAGES results uncovering a larger fluctuation in ratings from participant to participant in the NCLAGES results. The range is calculated based on the minimum and maximum scores on the MSLQ and NCLAGES results. The sizable range (5) on the MSLQ in relation to the performance assessment range (3.25) reiterates the degree of difference in variability of the two instruments.

Table 1.

Summary Statistics

\begin{tabular}{ccccccc}
\hline Instrument & $\mathrm{n}$ & Variance & $\begin{array}{c}\text { Standard } \\
\text { Deviation }\end{array}$ & $\begin{array}{c}\text { Standard } \\
\text { Error }\end{array}$ & Range \\
MSLQ & 101 & 0.28 & 0.53 & 0.05 & 3.25 \\
NCLAGES & 161 & 1.10 & 1.05 & 0.08 & 5 \\
\hline
\end{tabular}

A hypothesis test was conducted given the discrepancies in means and standard deviations of the MSLQ and NCLAGES participants indicated in Table 1. The Z-score was calculated using the following null hypothesis: There are no significant differences in means of the MSLQ and NCLAGES participants' perception survey results. Based on an analysis of the Z-statistic (33.32) and the proportional value $(<0.0001)$, the null hypothesis is rejected, providing evidence that there is a significant difference between the means of the student's overall survey results (refer to Table 2).

Table 2.

Hypothesis Test Results

\begin{tabular}{llllll}
\hline $\begin{array}{l}\text { MSLQ } \\
(\mathrm{n})\end{array}$ & $\begin{array}{l}\text { NCLAGES } \\
(\mathrm{n})\end{array}$ & $\begin{array}{l}\text { Sample } \\
\text { Mean }\end{array}$ & $\begin{array}{l}\text { Standard } \\
\text { Error }\end{array}$ & Z-Stat & P-value \\
101 & 161 & 3.27 & 0.10 & 33.32 & $<0.0001$ \\
\hline
\end{tabular}

Correlation coefficients were calculated to determine how strongly related the NCLAGES categorical groups (as prescribed by the CLASS survey) and the MSLQ items identified as continuing motivational and learning factors through the Motivation and Strategies for Learning in a Fundamentals of Graphics Education Course study. Thirty-six correlation coefficients were calculated. Each coefficient assists in determining the strength of the association between the variables (NCLAGES groups and the motivational and learning factors identified through the MSLQ previous study). These coefficients were calculated from MSLQ items 13 ("If I can, I want to get better grades in this class than most of the other students") in the Extrinsic Goal Orientation subgroup, item 18 ("If I try hard enough, then I will understand the course materials") in the Control of Learning Beliefs subgroup, item 20 ("I'm confident I can do an excellent job on the assignments and test in the this course"), and item 21 ("I expect to do well in this class") of the Self-Efficacy Learning Performance subgroup. Each item evaluated was 
identified by the Motivation and Strategies for Learning in a Fundamentals of Graphics Education Course study as continuing motivational and learning factors. These items were analyzed with the NCLAGES categorical groups: Real World Relations, Personal Interest, Sense Making, Conceptual Associations, Applied Understanding, Problem Solving, Confidence in Problem Solving, Advanced Problem Solving, and General Attitudes.

Based on the correlation results, there is statistical support that the two studies (attitudes and opinions of fundamentals of graphic students and Motivation and strategies for learning for fundamentals of graphics students) exhibit little or no correlation. This is evidenced by the strongest negative correlation (-0.11) on MSLQ item 18 paired with the NCLAGES Personal Interest group and the strongest positive correlation (0.21) on MSLQ item 21 in three of the NCLAGES groups: Real World Relations, Problem Solving, and General Attitudes.

\section{Conclusion and Recommendations}

No direct or strong correlations were found between the two areas of attitude from the NCLAGES instrument and motivation from the MSLQ instrument. Although weak, item 21 of the MSLQ "I expect to do well in this class," had the strongest positive correlation of the study but not deemed strong or moderate based on the correlation coefficient of 0.21 . Although this MSLQ item is weak in correlation, it was the one item that the researchers found to show any possible change of relationship from the two instruments looking at student attitude and their motivation in the classroom. A conclusion can be made based on this study that no direct relationship exists with this population that provides evidence that motivation to learn is related to student attitudes toward engineering and technical graphics, and vise versa.

Recommendations include use the NCLAGES and MSLQ surveys from this study with secondary engineering and technical graphics students to determine the role that academic level plays in determining student motivation to learn and attitude towards content and context. Instructor effectiveness as it pertains to student motivation and attitudes also needs careful study, especially in classroom settings where the courses are not required for students. More mixed methods analyses that span studies need to be conducted in our field of engineering and technical graphics. The researchers found little of this methodology used with the data collected in our field. It is requested that those professionals that teach research methods courses consider including this form of research and allow the field to mine its already existing data sources. Collaborations between researchers that employ these methods will contribute to a rich and integrated knowledge base for the field.

\section{Bibliography}

1. Wolters, C.A. \& Pintrich, P.R. (1999). Contextual differences in student motivation and self-regulated learning in mathematics, English, and social studies classrooms. Instructional Science, 26, 27-47.

2. Shell, J. \& Husman, D.F. (2008). Beliefs and perceptions about the future: A measurement of future time perspective. Learing and Individual Differences. 18, 166-175.

3. Knowles, M., Holton, E., \& Swanson, R. (1998). The adult learner: The definitive classic in adult education and human resource development. Burlington, MA: Gulf Professional Publishing. 
4. Johari, A.\& Bradshaw, A.C. (2008). Project-based learning in an internship program: A qualitative study of related roles and their motivational attributes. Education Technology Research and Development. 56(3), 329-359.

5. Vansteenkiste, M., Timmermans, T., Lens, W., Soenens, B., \& Van den Broeck, A. (2008). Does extrinsic goal framing enhance extrinsic goal-oriented individuals' learning and performance? An experimental test of the match perspective versus self-determination theory. Jounral of Educational Psychology, 387-397.8).

6. Bye, D., Pushkar, D., \& Conway, M. (2007). Motivation, interest, and positive affect in traditional and nontraditional undergraduate students. Adult Education Quarterly, 57(2). 141-158.

7. Pintrich, P.R. (1999). The role of motivation in promoting and sustaining self-regulated learning. International Journal of Educational Research. 31(6), 459-470.

8. Yang, N.D. (1999). The relationship between EFL learners' beliefs and learning strategy use. System. 27(4), 515-535.

9. Adams, W. K., Perkins, K. K., Podolefsky, N. S., Dubson, M., Finkelstein, N. D., \& Wieman, C. E. (2006). A new instrument for measuring student beliefs about physics and learning physics: The Colorado Learning Attitudes about Science Survey. Physical Review Special Topics: Physics Education Research, 2(1), 101-115.

10. Hein, T.L. \& Budny, D.D. (November, 1999). Teaching to students' learning styles: Approaches that work. Published Proceedings of the ASEE/IEEE Frontiers in Education Conference, San Juan, Puerto Rico, Session 12c1.

11. McIntosh, H., Berman, S.H. \& Youniss, J. (2007). An interim report on the evaluation of a comprehensive high school civic engagement intervention in Hudson, MA, Center for Information and Research on Civic Learning and Engagement (CIRCLE). 22-58.

12. Durik, A.M. \& Harackiewicz, J.M. (2007). Different strokes for different folks: how individual interest moderates the effects of situational factors on task interest. Journal of Educational Psychology, 99(3), 597-610.

13. Lieberman, D.A. \& Remedios, R. (2007). Do undergraduates' motives for studying change as they progress through their degrees?. British Journal of Educational Psychology, 77, 379-395.

14. Adams, W. K., Perkins, K. K., Podolefsky, N. S., Dubson, M., Finkelstein, N. D., \& Wieman, C. E. (2006). A new instrument for measuring student beliefs about physics and learning physics: The Colorado Learning Attitudes about Science Survey. Physical Review Special Topics: Physics Education Research, 2(1), 101-115.

15. Pintrich, P. R., Smith, D. A. F., Garcia, T., \& McKeachie, W. J. (1993). Reliability and predictive validity of the Motivated Strategies for Learning Questionnaire (MSLQ). Educational and Psychological Measurement, 53, 801-813.

16. Duncan, T.G. \& McKeachie, W.J. (2005). The making of the Motivated Strategies for Learning Questionnaire. Educational Psychologist. 40(2), 117-128.

17. Clark, A. C., Ernst, J. V., \& Scales, A. Y. (2008). The attitudes and opinions of students toward technical graphics: Preliminary survey results. Published Proceedings of the Annual Conference of the American Society of Engineering Education, Pittsburg, PA, Session AC 2005-847.

18. Clark, A. C., Ernst, J. V., \& Scales, A. Y. (2009). Motivation and strategies for learning in a fundamentals of graphics education course. Published proceedings of the $64^{\text {th }}$ Mid-Year Meeting of the Engineering Design Graphics Division of the American Society of Engineering Education, Berkley, CA. 